\title{
Is Extrapolation of the Safety and Efficacy Data in One Indication to Another Appropriate for Biosimilars?
}

\author{
Howard Lee ${ }^{1,2}$
}

Received 31 July 2013; accepted 19 September 2013; published online 11 October 2013

\begin{abstract}
CT-P13, the world's first biosimilar monoclonal antibody to infliximab, was approved for marketing in South Korea for all the six indications of infliximab, which Europe may follow, although the product was tested only in rheumatoid arthritis (RA) with a limited pharmacokinetic comparison in ankylosing spondylitis. However, the extrapolation of the efficacy and safety findings of CT-P13 in RA to the other indications appears scientifically challenging when assessed by the current regulatory requirements. RA is not a sensitive clinical model to detect potential differences between CT-P13 and infliximab, and other mechanisms of action than antagonizing tumor necrosis factor $\alpha$ appear to be also important, which could be different by the approved indications. Furthermore, the immunogenicity and safety profiles of CT-P13 were not sufficiently characterized in that immunogenicity potential was lowest in RA, which was even further suppressed by the concomitant use of methotrexate. Extrapolation of the safety and efficacy data in one indication to another may be inappropriate for biosimilars unless backed up by strong scientific justification, which may include the mechanistic exposure-relationship approach. Therefore, regulatory agencies need to exercise caution before granting extrapolated indications to biosimilars.
\end{abstract}

KEY WORDS: biosimilars; CT-P13; extrapolation of indication; infliximab; regulatory agency.

\section{INTRODUCTION}

In July 2012, the Korea Food and Drug Administration (KFDA, currently the Korean Ministry of Food and Drug Safety) approved CT-P13 (Remsima® ${ }^{\circledR}$, Celltrion), the world's first follow-on monoclonal antibody claimed to be biosimilar to infliximab (Remicade ${ }^{\circledR}$, Janssen Biotech) (1). A year later, the European Medicines Agency (EMA) also recommended the marketing authorization of CT-P13 (2). The approval or recommended approval of CT-P13 was based on a single equivalence trial conducted in patients with rheumatoid arthritis (RA) (3), supplemented by a pharmacokinetic study on ankylosing spondylitis (AS) (4). What was unique about this approval was that four other indications of infliximab (i.e., Crohn's disease, ulcerative colitis, psoriatic arthritis, and plaque psoriasis) were granted to CT-P13 although the product was not tested in these indicated populations.

According to KFDA, it may be possible to extrapolate the efficacy and safety data of the follow-on biological product in one indication to the other indications of a reference biological product when all of the following conditions are met (5): (1) a sensitive clinical test model has been used that is able to detect potential differences between the follow-on and reference products; (2) the clinically

\footnotetext{
${ }^{1}$ Clinical Trials Center, Department of Clinical Pharmacology and Therapeutics, Seoul National University Hospital, 101 Daehak-ro, Jongno-gu Seoul 110-744, South Korea.

${ }^{2}$ To whom correspondence should be addressed. (e-mail: howardlee@snu.ac.kr)
}

relevant mechanisms of action and/or the involved receptors are the same for the different indications; and (3) the safety and immunogenicity profiles of the follow-on product have been sufficiently characterized. The same requirements are found in the guidance by the World Health Organization (WHO) (6), whereas the US FDA appears to require more strict and detailed criteria for extrapolation across indications (e.g., the most sensitive clinical condition to detect clinically meaningful difference not only in efficacy, but also in safety including immunogenicity; caution for different safety risk profiles across indications due to different comorbidities and concomitant medications; added shield against different toxicities based on off-target effects as well as the enhanced pharmacological activity of the product; and scientific justification in terms of the pharmacokinetics and bio-distribution of the product in different patient populations) (7). EMA also provides a legal mechanism for possible extrapolation to other indications (8) (Table I). The objective of this paper is to discuss whether CT-P13 met the extrapolation requirements by the regulatory agencies, particularly KFDA, based on existing scientific and clinical data.

\section{EXTRAPOLATION REQUIREMENTS}

\section{Is Rheumatoid Arthritis a Sensitive Clinical Model?}

If the difference in efficacy between a treatment and placebo is small, it is difficult (i.e., less sensitive) to show a difference between the treatment and another treatment similar to that even 
Table I. Summary of Concerns and Current Thoughts of FDA, EMA, and WHO (KFDA) Regarding Extrapolation of Clinical Data for Follow-on Biological Products

\begin{tabular}{|c|c|c|c|}
\hline Concern & FDA & EMA & KFDA (WHO) \\
\hline $\begin{array}{l}\text { MOA may be distinct in } \\
\text { each therapeutic } \\
\text { indication. }\end{array}$ & \multicolumn{2}{|c|}{$\begin{array}{l}\text { Extrapolation will be considered on a case-by-case basis. Where the } \\
\text { MOA differs between indications or are not fully understood, } \\
\text { separate clinical trials are likely to be necessary. }\end{array}$} & $\begin{array}{l}\text { The clinically relevant mechanisms of } \\
\text { action and/or the involved receptors } \\
\text { should be the same for the different } \\
\text { indications. }\end{array}$ \\
\hline $\begin{array}{l}\text { For a given MOA, several } \\
\text { mechanisms may exist. }\end{array}$ & \multicolumn{2}{|c|}{$\begin{array}{l}\text { Almost superimposable biological data must be provided, covering } \\
\text { all functional aspects of the agent, even if not considered clinically } \\
\text { relevant. Where MOA are not fully understood, separate clinical } \\
\text { trials are likely to be necessary. }\end{array}$} & See above. \\
\hline $\begin{array}{l}\text { Risk of undertreating } \\
\text { patients/varied safety } \\
\text { profiles in different } \\
\text { patient groups. }\end{array}$ & \multicolumn{2}{|c|}{$\begin{array}{l}\text { Data should be produced using a patient population and clinical } \\
\text { endpoint most sensitive to detect clinically meaningful differences } \\
\text { in efficacy and safety. }\end{array}$} & $\begin{array}{l}\text { A sensitive clinical test model should be } \\
\text { used that is able to detect potential } \\
\text { differences between the follow-on and } \\
\text { reference products. } \\
\text { The safety and immunogenicity profiles of } \\
\text { the follow-on product should be } \\
\text { sufficiently characterized. }\end{array}$ \\
\hline $\begin{array}{l}\text { Individual patient } \\
\text { characteristics may } \\
\text { influence the } \\
\text { response. }\end{array}$ & $\begin{array}{l}\text { Careful consideration must be } \\
\text { given to comorbidities/ } \\
\text { concomitant medications and } \\
\text { intersubject variability. }\end{array}$ & $\begin{array}{l}\text { Homogeneous population should } \\
\text { be used-differences in } \\
\text { response can then be } \\
\text { attributed to the biosimilar. }\end{array}$ & \\
\hline
\end{tabular}

Modified from a table by T. Dörner et al. (37) as courtesy

FDA Food and Drug Administration, EMA European Medicines Agency, KFDA Korea Food and Drug Administration, WHO World Health Organization, $M O A$ mechanism of action

if there is. Suppose that there is a $20 \%$ clinically significant difference in efficacy between a reference product and its follow-on product. If the placebo-adjusted efficacy of the reference product is sufficiently large, e.g., 50 with 100 being the maximum attainable efficacy, the $20 \%$ difference will be 10 , which may be detected rather easily. However, if the placebo-adjusted efficacy of the reference product is only 5 , the difference that needs to be detected becomes extremely small (i.e., 1). To detect such a small difference with a sufficient power, the trial has to enroll a huge number of subjects; otherwise, the trial will not be sensitive enough.

That is why the noninferiority (or equivalence) margin for follow-on products should be narrow when the difference in efficacy between a reference product and placebo is small (9). The margin cannot be greater than the placebo-adjusted treatment effect of a reference product, often referred to as "M1" or the largest margin. Therefore, a narrow margin can offset the insensitiveness of a noninferiority or equivalence trial when the placebo-adjusted efficacy of a reference product is small. From the regulator's point of view, this is reasonable because it can guard against the consumer risk of erroneously declaring the follow-on product to be noninferior or equivalent when, in fact, it is inferior or nonequivalent, respectively, to a reference product.

Of the six indications of infliximab, the greatest placeboadjusted response was found in plaque psoriasis, followed by psoriatic arthritis and Crohn's disease (Table II). In contrast, RA was associated with the smallest placebo-adjusted response to infliximab (8-25\%, Table II). Given that "widely differing protein levels have the same clinical effect" for therapeutic proteins (10), the dosing in RA may be less than optimal to be sensitive enough. In fact, the label-recommended dose of infliximab in RA is $40 \%$ lower than the one in the other indications for both induction and maintenance regimens (i.e., 3 vs. $5 \mathrm{mg} / \mathrm{kg}$ at 0,2 , and 6 weeks, then every 8 weeks, respectively) because infliximab is used as an add-on treatment in conjunction with methotrexate (11). However, additional efficacy was obtained with infliximab doses of $>3 \mathrm{mg} / \mathrm{kg}$ in RA, e.g., up to $42 \%$ placebo-adjusted response $(12,13)$, which was 1.7 times as large as that seen with $3 \mathrm{mg} / \mathrm{kg}$. The increased efficacy with higher doses of infliximab is also reflected in the label, which recommends "for some patients... increasing the dose up to $10 \mathrm{mg} / \mathrm{kg}$ or treating as often as every 4 weeks" (11).

In the equivalence study on CT-P13 in RA, CT-P13 or infliximab was given at a lower induction and maintenance doses of $3 \mathrm{mg} / \mathrm{kg}$ at 0,2 , and 6 weeks and then every 8 weeks throughout the entire study period, respectively (3). In this equivalence study, the $95 \%$ confidence interval for the treatment difference between CT-P13 and infliximab in the primary endpoint (i.e., ACR20 response at week 30) was $-6 \%$ to $10 \%$ and $-4 \%$ to $12 \%$, respectively, for the intentionto-treat and per-protocol populations. Thus, these confidence intervals contained the smallest placebo-adjusted response to infliximab shown previously (i.e., $8 \%$ ), although they fell within the range of the equivalence margin of $-15 \%$ to $15 \%$. In other words, RA is likely to be a less, if not the least, sensitive clinical model to detect a potential difference in efficacy between CT-P13 and infliximab, particularly as studied in the equivalence trial of CT-P13. Therefore, the similar efficacy between CT-P13 and infliximab in RA may not rule out the possibility that the efficacies of the two products are in fact different in other extrapolated indications, in which such differences can be more easily detected because they are more sensitive clinical models than RA.

\section{Is Antagonizing Tumor Necrosis Factor Alpha the Same Mechanism of Action in All the Approved Indications of Infliximab?}

The mechanism of action of therapeutic monoclonal antibodies is multifaceted, which has been only partially elucidated (14). Although both infliximab and etanercept antagonize tumor 
Table II. Efficacy of Infliximab in the Approved Indications

\begin{tabular}{|c|c|c|c|c|c|c|}
\hline \multirow[b]{2}{*}{ Indication } & \multirow[b]{2}{*}{ Study } & \multirow[b]{2}{*}{ Efficacy Endpoint } & \multirow[b]{2}{*}{ Week } & \multicolumn{3}{|c|}{ Response, \% } \\
\hline & & & & Infliximab & Placebo & Difference $^{\mathrm{a}}$ \\
\hline \multirow[t]{5}{*}{ Crohn's disease } & Targan et al. (18) & Clinical response & 4 & 81 & 16 & 65 \\
\hline & & Clinical response & 12 & 41 & 12 & 29 \\
\hline & ACCENT I (15) & Clinical remission & 30 & 42 & 21 & 21 \\
\hline & Present et al. (16) & Fistula response & 6 & 68 & 26 & 42 \\
\hline & ACCENT II (17) & Fistula response & 54 & 46 & 23 & 23 \\
\hline \multirow[t]{5}{*}{ Ulcerative colitis } & UC I (38) & Clinical response & 8 & 69 & 37 & 32 \\
\hline & & Clinical response & 30 & 52 & 30 & 22 \\
\hline & & Clinical response & 54 & 45 & 20 & 25 \\
\hline & UC II (38) & Clinical response & 8 & 65 & 29 & 36 \\
\hline & & Clinical response & 30 & 47 & 26 & 21 \\
\hline \multirow[t]{6}{*}{ Rheumatoid arthritis } & ATTRACT (12) & ACR20 & 54 & 42 & 17 & 25 \\
\hline & & ACR50 & 54 & 21 & 9 & 12 \\
\hline & & ACR70 & 54 & 11 & 2 & 9 \\
\hline & ASPIRE (13) & ACR20 & 54 & 62 & 54 & 8 \\
\hline & & ACR50 & 54 & 46 & 32 & 14 \\
\hline & & ACR70 & 54 & 33 & 21 & 12 \\
\hline \multirow[t]{3}{*}{ Ankylosing spondylitis } & ASSERT (39) & ASAS20 & 24 & 61 & 19 & 42 \\
\hline & & ASAS50 & 24 & 47 & 12 & 35 \\
\hline & & ASAS70 & 24 & 28 & 4 & 24 \\
\hline \multirow[t]{6}{*}{ Psoriatic arthritis } & IMPACT 1 (40) & ACR20 & 16 & 66 & 10 & 56 \\
\hline & & ACR50 & 16 & 46 & 0 & 46 \\
\hline & & ACR70 & 16 & 29 & 0 & 29 \\
\hline & IMPACT 2 (41) & ACR20 & 24 & 54 & 16 & 38 \\
\hline & & ACR50 & 24 & 41 & 4 & 37 \\
\hline & & ACR70 & 24 & 27 & 2 & 25 \\
\hline \multirow[t]{3}{*}{ Plaque psoriasis } & EXPRESS (30) & PASI 75 & 10 & 80 & 3 & 77 \\
\hline & EXPRESS II (29) & PASI 75 & 10 & 76 & 2 & 74 \\
\hline & SPIRIT (42) & PASI 75 & 10 & 88 & 6 & 82 \\
\hline
\end{tabular}

ACR20, ACR50, and ACR70 American College of Rheumatology 20\%, 50\%, and 70\% response criteria, respectively; ASAS20, ASAS50, and ASAS70 Assessments in Ankylosing Spondylitis 20\%, 50\%, and 70\% response criteria, respectively; PASI75 $75 \%$ reduction in the Psoriasis Area and Severity Index score

${ }^{a}$ Placebo-adjusted difference (i.e., infliximab-placebo) in percentage point

necrosis factor alpha (TNF- $\alpha$ ), this shared mechanism of action does not translate into similar efficacy. For example, infliximab is efficacious in Crohn's disease (15-18), whereas etanercept is not (19) even though both infliximab and etanercept are effective to treat RA $(12,13,20)$. Even for the same monoclonal antibody, different mechanisms of action other than antagonizing TNF- $\alpha$ appear to be prevailing in the treatment of Crohn's disease and RA. For instance, infliximab induced apoptosis of inflammatory cells in Crohn's disease (21), whereas it did not exert the same effect in RA (22). Furthermore, infliximab attaches to and inhibits membrane-bound TNF- $\alpha$ much stronger than etanercept (23). This stronger target affinity of infliximab may lead to several intracellular mechanisms of action, which makes extrapolation of the efficacy and safety data of infliximab scientifically more challenging (24). Collectively, these findings suggest that the clinically relevant mechanisms of action for infliximab, and thereby for CT-P13, could differ by the approved indications.

\section{Have the Safety and Immunogenicity Profiles of CT-P13 Been Sufficiently Characterized?}

Antidrug antibodies or unwanted immunogenicity is a primary safety concern for biologics, and follow-on products are not an exception $(25,26)$. For example, a minor change in the manufacturing process of an erythropoietin product caused the generation of autoantibodies to endogenous as well as exogenous erythropoietin, drastically increasing the incidence of pure red cell aplasia, a rare but fatal anemic condition (27). Similarly, after treatment with infliximab in Crohn's disease, antibodypositive patients were 2.9 times more likely to experience infusion reactions than antibody-negative patients (28).

Therefore, the regulatory agencies require that the immunogenicity profile of follow-on products be sufficiently characterized before extrapolation to other indications is sought (5-8). Furthermore, the immunogenicity profile should be studied "in the patient population that carries the highest risk of an immune response and immune-related adverse events" (emphasis added) (6). This requirement is scientifically justified as discussed in the previous section, i.e., the population with the highest immune response will be the most sensitive population to detect a possible difference in immunogenicity (7). In the same vein, a population for which immunogenicity is suppressed by any measure may not serve as a basis for extrapolation to other indications (6).

The proportion of patients developing immunogenicity after treatment with infliximab varied widely by indication; it was highest in Crohn's disease (up to 61\%) (28) and ranging between 20 and $51 \%$ in psoriasis $(29,30)$. RA, however, is the indication in which the smallest proportion of patients developed antibodies to infliximab $(\sim 10 \%)$, mostly at a low titer 
$(12,13,31,32)$. This low immunogenicity in RA may be related to co-administered methotrexate, an immunosuppressant (28). In other words, RA is not only a less sensitive population for detecting a difference in immunogenicity, but also an inappropriate population for extrapolation due to the mandatory use of methotrexate in addition to infliximab. Therefore, the immunogenicity profile of CT-P13, investigated mainly in RA, may not be extrapolated to the other indications of infliximab. This means that the safety profiles of CT-P13 in patients with Crohn's disease, ulcerative colitis, psoriatic arthritis, and plaque psoriasis may differ from those with RA.

\section{CONCLUSION}

As exemplified in the case of CT-P13, a follow-on infliximab, extrapolation of the safety and efficacy data in one indication to another is scientifically challenging for biosimilars, particularly when extrapolation is based on a less sensitive clinical indication such as RA. This notion has been recently shared by experts in the inflammatory bowel disease (IBD) groups, who emphasized the difficulty of "extrapolation across indications" for biosimilars (33) and required "rigorous testing in patients with IBD" (34). Their positions are appropriate in that most health-care professionals are not aware how and on what basis biosimilars are approved for marketing (35). Therefore, the regulatory agencies need to exercise caution before granting extrapolated indications to biosimilars, many of which might be hard to justify by the current regulatory standards unless backed up by strong scientific rationale. On the other hand, it should be also noted that extrapolation across indications is a keystone to the marketing approval of biosimilars because their development process is "abridged" in principle. In this regard, the exposureresponse relationship approach based on extensive modeling and simulation experiments using a short-term clinical outcome variable or validated pharmacodynamic endpoint can be a practical alternative to the full-scale comparative clinical trials. This approach has been shown to be effective in the drug development program of etanercept, in which mechanistic modeling and simulation enabled the extrapolation of a new dosage regimen to untested indications (36). Of course, the exposure-response relationship approach should be applied on a case-by-case basis until its usefulness and validity is carefully assessed for biosimilars, which will be elucidated eventually as more complex biosimilars including monoclonal antibody are currently under development.

Conflict of Interest The author has no conflict of interest to declare.

\section{REFERENCES}

1. Biosimilar News. World's first biosimilar antibody is approved in Korea 7/23/2012. http://www.biosimilarnews.com/worlds-firstbiosimilar-antibody-is-approved-in-korea (2012) Accessed 2 Mar 2013

2. European Medicines Agency. European Medicines Agency recommends approval of first two monoclonal-antibody biosimilars. http:// www.ema.europa.eu/ema/index.jsp?curl=pages/news_and_events/ news/2013/06/news_detail_001837.jsp\&mid=WC0b01ac058004d5c1 (2013). Accessed 29 Jul 2013

3. Yoo DH, Hrycaj P, Miranda P, Ramiterre E, Piotrowski M, Shevchuk S, et al. A randomised, double-blind, parallel-group study to demonstrate equivalence in efficacy and safety of CTP13 compared with innovator infliximab when coadministered with methotrexate in patients with active rheumatoid arthritis: the PLANETRA study. Ann Rheum Dis. 2013;72(10):1613-20. doi:10.1136/annrheumdis-2012-203090.

4. Park W, Hrycaj P, Jeka S, Kovalenko V, Lysenko G, Miranda P, et al. A randomised, double-blind, multicentre, parallel-group, prospective study comparing the pharmacokinetics, safety, and efficacy of CT-P13 and innovator infliximab in patients with ankylosing spondylitis: the PLANETAS study. Ann Rheum Dis. 2013;72(10):1605-12. doi:10.1136/annrheumdis-2012-203091.

5. Korea Food and Drug Administration. National Institute of Food and Drug Safety Evaluation. Guidelines on the evaluation of biosimilar products. Chungcheongbuk-do: Korea Food and Drug Administration; 2010

6. World Health Organization. Guidelines on evaluation of similar biotherapeutic products (SBPs). Geneva: World Health Organization; 2009

7. Food and Drug Administration, Center for Drug Evaluation and Research (CDER), Center for Biologics Evaluation and Research (CBER). Guidance for industry. Scientific considerations in demonstrating biosimilarity to a reference product (draft). Rockville: Food and Drug Administration; 2012

8. European Medicines Agency. Guideline on similar biological medicinal products containing monoclonal antibodies (EMA/ CHMP/BMWP/403543/2010). London: European Medicines Agency; (2010)

9. Food and Drug Administration, Center for Drug Evaluation and Research (CDER), Center for Biologics Evaluation and Research (CBER). Guidance for industry. Non-inferiority clinical trials (Draft). Rockville: Food and Drug Administration; 2010

10. Schellekens H, Moors E. Clinical comparability and European biosimilar regulations. Nat Biotechnol. 2010;28(1):28-31. doi:10.1038/nbt0110-28.

11. Centocor Inc. Label for Infliximab (REMICADE). http:// www.accessdata.fda.gov/drugsatfda_docs/label/2013/ 103772s5345lbl.pdf (2013). Accessed 2 Sep 2013

12. Lipsky PE, van der Heijde DM, St Clair EW, Furst DE, Breedveld FC, Kalden JR, et al. Infliximab and methotrexate in the treatment of rheumatoid arthritis. Anti-Tumor Necrosis Factor Trial in Rheumatoid Arthritis with Concomitant Therapy Study Group. N Engl J Med. 2000;343(22):1594-602. doi:10.1056/ NEJM200011303432202.

13. St Clair EW, van der Heijde DM, Smolen JS, Maini RN, Bathon $\mathrm{JM}$, Emery P, et al. Combination of infliximab and methotrexate therapy for early rheumatoid arthritis: a randomized, controlled trial. Arthritis Rheum. 2004;50(11):3432-43. doi:10.1056/ NEJM199710093371502.

14. Golay J, Introna M. Mechanism of action of therapeutic monoclonal antibodies: promises and pitfalls of in vitro and in vivo assays. Arch Biochem Biophys. 2012;526(2):146-53. doi:10.1016/j.abb.2012.02.011.

15. Hanauer SB, Feagan BG, Lichtenstein GR, Mayer LF, Schreiber $\mathrm{S}$, Colombel JF, et al. Maintenance infliximab for Crohn's disease: the ACCENT I randomised trial. Lancet. 2002;359(9317):1541-9. doi:10.1016/S0140-6736(02)08512-4.

16. Present DH, Rutgeerts P, Targan S, Hanauer SB, Mayer L, van Hogezand RA, et al. Infliximab for the treatment of fistulas in patients with Crohn's disease. N Engl J Med. 1999;340(18):1398405. doi:10.1056/NEJM199905063401804.

17. Sands BE, Anderson FH, Bernstein CN, Chey WY, Feagan BG, Fedorak RN, et al. Infliximab maintenance therapy for fistulizing Crohn's disease. N Engl J Med. 2004;350(9):876-85. doi:10.1056/ NEJMoa030815.

18. Targan SR, Hanauer SB, van Deventer SJ, Mayer L, Present DH, Braakman T, et al. A short-term study of chimeric monoclonal antibody cA2 to tumor necrosis factor alpha for Crohn's disease. Crohn's Disease cA2 Study Group. N Engl J Med. 1997;337(15):1029-35.

19. Sandborn WJ, Hanauer SB, Katz S, Safdi M, Wolf DG, Baerg $\mathrm{RD}$, et al. Etanercept for active Crohn's disease: a randomized, 
double-blind, placebo-controlled trial. Gastroenterology. 2001;121(5):1088-94. doi:10.1053/gast.2001.28674.

20. Weinblatt ME, Kremer JM, Bankhurst AD, Bulpitt KJ, Fleischmann RM, Fox RI, et al. A trial of etanercept, a recombinant tumor necrosis factor receptor:Fc fusion protein, in patients with rheumatoid arthritis receiving methotrexate. New Engl J Med. 1999;340(4):253-9. doi:10.1056/NEJM199901283400401.

21. van den Brande JMH, Braat H, van den Brink GR, Versteeg $\mathrm{HH}$, Bauer CA, Hoedemaeker I, et al. Infliximab but not etanercept induces apoptosis in lamina propria T-lymphocytes from patients with Crohn's disease. Gastroenterology. 2003;124(7):1774-85. doi:10.1016/S0016-5085(03)00382-2.

22. Smeets TJM, Kraan MC, van Loon ME, Tak P-P. Tumor necrosis factor $\alpha$ blockade reduces the synovial cell infiltrate early after initiation of treatment, but apparently not by induction of apoptosis in synovial tissue. Arthritis Rheum. 2003;48(8):215562. doi:10.1002/art.11098.

23. Horiuchi T, Mitoma H, Harashima S-i, Tsukamoto H, Shimoda T. Transmembrane TNF- $\alpha$ : structure, function and interaction with anti-TNF agents. Rheumatology. 2010;49(7):1215-28. doi:10.1093/rheumatology/keq031.

24. Reichert JM. Next generation and biosimilar monoclonal antibodies: essential considerations towards regulatory acceptance in Europe. February 3-4, 2011, Freiburg, Germany. MAbs. 2011;3(3):223-40. doi:10.4161/mabs.3.3.15475.

25. Schellekens H. Biosimilar therapeutics-what do we need to consider? NDT Plus. 2009;2(Suppl_1):i27-36. doi:10.1093/ndtplus/sfn177.

26. Kessler M, Goldsmith D, Schellekens H. Immunogenicity of biopharmaceuticals. Nephrol Dial Transplant. 2006;21 Suppl 5:v9-v12. doi:10.1093/ndt/gfl476.

27. Schellekens H. Immunologic mechanisms of EPO-associated pure red cell aplasia. Best Pract Res Clin Haematol. 2005;18(3):473-80. doi:10.1016/j.beha.2005.01.016.

28. Baert F, Noman M, Vermeire S, van Assche G, D'Haens G, Carbonez A, et al. Influence of immunogenicity on the long-term efficacy of infliximab in Crohn's disease. N Engl J Med. 2003;348(7):601-8. doi:10.1056/NEJMoa020888.

29. Menter A, Feldman SR, Weinstein GD, Papp K, Evans R, Guzzo $\mathrm{C}$, et al. A randomized comparison of continuous vs. intermittent infliximab maintenance regimens over 1 year in the treatment of moderate-to-severe plaque psoriasis. J Am Acad Dermatol. 2007;56(1):31-15. doi:10.1016/j.jaad.2006.07.017.

30. Reich K, Nestle FO, Papp K, Ortonne JP, Evans R, Guzzo C, et al. Infliximab induction and maintenance therapy for moderate-tosevere psoriasis: a phase III, multicentre, double-blind trial. Lancet. 2005;366(9494):1367-74. doi:10.1016/S0140-6736(05)67566-6.

31. Maini R, St Clair EW, Breedveld F, Furst D, Kalden J, Weisman M, et al. Infliximab (chimeric anti-tumour necrosis factor alpha monoclonal antibody) versus placebo in rheumatoid arthritis patients receiving concomitant methotrexate: a randomised phase III trial. ATTRACT Study Group. Lancet. 1999;354(9194):1932-9. doi:10.1016/S01406736(99)05246-0.

32. Flood J. Tumor necrosis factor inhibitors in the treatment of chronic inflammatory diseases. A review of immunogenicity and potential implications. Manag Care. 2009;18(4 Suppl 3):1-5.

33. Gecse KB, Khanna R, van den Brink GR, Ponsioen CY, Lowenberg M, Jairath V, et al. Biosimilars in IBD: hope or expectation? Gut. 2013;62(6):803-7. doi:10.1136/gutjnl-2012303824.

34. Danese S, Gomollon F, Governing Board and Operational Board of ECCO. ECCO position statement: the use of biosimilar medicines in the treatment of inflammatory bowel disease (IBD). J Crohns Colitis. 2013;7(7):586-9. doi:10.1016/j.crohns.2013.03.011.

35. Kay J. Biosimilars: a regulatory perspective from America. Arthritis Res Ther. 2011;13(3):112. doi:10.1186/ar3310.

36. Lee H, Yim DS, Zhou H, Peck CC. Evidence of effectiveness: how much can we extrapolate from existing studies? AAPS J. 2005;7(2):E467-74. doi:10.1208/aapsj070247.

37. Dorner T, Strand V, Castaneda-Hernandez G, Ferraccioli G, Isaacs JD, Kvien TK, et al. The role of biosimilars in the treatment of rheumatic diseases. Ann Rheum Dis. 2013;72(3):322-8. doi:10.1136/ annrheumdis-2012-202715.

38. Rutgeerts P, Sandborn WJ, Feagan BG, Reinisch W, Olson A, Johanns $\mathrm{J}$, et al. Infliximab for induction and maintenance therapy for ulcerative colitis. N Engl J Med. 2005;353(23):246276. doi:10.1056/NEJMoa050516.

39. van der Heijde D, Dijkmans B, Geusens P, Sieper J, Dewoody K, Williamson P, et al. Efficacy and safety of infliximab in patients with ankylosing spondylitis: results of a randomized, placebocontrolled trial (ASSERT). Arthritis Rheum. 2005;52(2):582-91. doi:10.1002/art.20852.

40. Antoni CE, Kavanaugh A, Kirkham B, Tutuncu Z, Burmester GR, Schneider U, et al. Sustained benefits of infliximab therapy for dermatologic and articular manifestations of psoriatic arthritis: results from the infliximab multinational psoriatic arthritis controlled trial (IMPACT). Arthritis Rheum. 2005;52(4):122736. doi:10.1002/art.20967.

41. Antoni C, Krueger GG, de Vlam K, Birbara C, Beutler A, Guzzo C, et al. Infliximab improves signs and symptoms of psoriatic arthritis: results of the IMPACT 2 trial. Ann Rheum Dis. 2005;64(8):1150-7. doi:10.1136/ard.2004.032268.

42. Gottlieb AB, Evans R, Li S, Dooley LT, Guzzo CA, Baker D, et $a l$. Infliximab induction therapy for patients with severe plaquetype psoriasis: a randomized, double-blind, placebo-controlled trial. J Am Acad Dermatol. 2004;51(4):534-42. doi:10.1016/ j.jaad.2004.02.021. 